\title{
Characteristics of abstainers from substance use and antisocial behavior in the United States
}

\author{
Michael G. Vaughn ${ }^{\mathrm{a}, *}$, Qiang Fu ${ }^{\mathrm{b}}$, Stephen J. Wernet ${ }^{\mathrm{c}}$, Matt DeLisi ${ }^{\mathrm{d}}$, Kevin M. Beaver ${ }^{\mathrm{e}}$, \\ Brian E. Perron ${ }^{\mathrm{f}}$, Matthew O. Howard ${ }^{\mathrm{g}}$ \\ a School of Social Work and Department of Community Health, Division of Epidemiology, School of Public Health, Saint Louis University, St, Louis, MO 63103, United States \\ ${ }^{b}$ Department of Biostatistics, School of Public Health, Saint Louis University, St. Louis, MO, United States \\ c School of Social Work, Saint Louis University, St, Louis, MO 63103, United States \\ d Criminology and Criminal Justice Studies, Department of Sociology, Iowa State University, Ames, IA, United States \\ e College of Criminology and Criminal Justice, Florida State University, Tallahassee, FL, United States \\ ${ }^{f}$ School of Social Work, University of Michigan, Ann Arbor, MI, United States \\ g School of Social Work, University of North Carolina, Chapel Hill, NC, United States
}

\section{A R T I C L E I N F O}

Available online 5 March 2011

\begin{abstract}
A B S T R A C T
Purpose: Whether lifetime abstainer's antisocial behavior is maladjusted or well-adjusted is unresolved. The aim of this study was to compare abstainers (defined as persons with no lifetime use of alcohol and other drugs and non-engagement in antisocial or delinquent behavior) with non-abstainers across a range of sociodemographic and mental health characteristics in the United States.

Methods: Data were derived from the National Epidemiologic Survey on Alcohol and Related Conditions, a nationally representative sample of U.S. adults. Structured psychiatric interviews $(N=43,093)$ using the Alcohol Use Disorder and Associated Disabilities Interview Schedule - DSM-IV version (AUDADIS-IV) were completed by trained lay interviewers between 2001 and 2002.

Results: The prevalence of abstaining was 11 percent. Abstainers were significantly more likely to be female, Asian and African-American, born outside the U.S., and less likely to be unemployed. Multivariate logistic regression analyses revealed that abstainers were significantly less likely to evidence lifetime mood, anxiety, or personality disorder compared to non-abstainers.

Conclusions: Findings indicate that abstainers are not maladapted and are comparatively more functional than non-abstainers.
\end{abstract}

(c) 2011 Elsevier Ltd. All rights reserved.

\section{Introduction}

Engaging in a delinquent act or using a substance such as alcohol over the life-course is thought to be normative. Studies indicate that during adolescence most youths will engage in some form of delinquency and substance experimentation (DeLisi, 2001; Elliott, Huizinga, \& Menard, 1989; Moffitt, 1993. Abstainers are individuals who have not used any psychoactive substances or have not committed

\footnotetext{
is NESARC was funded by the National Institute on Alcohol Abuse and Alcoholism with additional support provided by the National Institute on Drug Abuse. The authors are grateful for support from NIH grants: DA021405 (Dr. Howard), K07CA104119 (Dr. Fu), P50 HD052117 from the Eunice Kennedy Shriver National Institute Of Child Health and Human Development, the Greater Texas Foundation and the Meadows Center for Preventing Educational Risk at the University of Texas at Austin. The contents of the article are solely the responsibility of the authors and do not necessarily represent the official view of the National Institutes of Health.

* Corresponding author at: Tegeler Hall, 3550 Lindell Boulevard, St. Louis, MO 63103. Tel.: + 13149772718 .

E-mail address: mvaughn9@slu.edu (M.G. Vaughn).
}

any delinquent or antisocial act. It has been theorized that because abstaining behavior is abnormal in a statistical sense that abstainers are therefore suffering from some form of psychopathology. Abstainers are thought to lack interpersonal skills and are therefore loners, avoid close personal relationships, are emotionally and behaviorally bland and are perhaps sad and depressed due to their isolation. Furthermore, abstainers are purported to be overly conscientious, highly conservative, and moralistic. Many of these notions, while theoretically plausible, have been developed from a limited empirical foundation. In an important study, Shedler and Block (1990) did find that abstainers may have impaired psychological well-being and are generally anxious. In contrast, persons who engage in moderate substance use are thought to be expressive, sociable, and fit in well with others.

In a seminal work, Moffitt (1993) hypothesized that abstainers are inhibited from opportunities to learn and engage in antisocial behavior because they possess certain characteristics such as social anxiousness. Thus, Moffitt speculated that abstaining may be due to something intrinsic about the individual that results in social isolation and lack of encountering the standard opportunities, such as peer contagion, that 
lead to engagement in delinquency or drug use. This possibility was tested by Piquero, Brezina, and Turner (2005) using data from the National Longitudinal Survey of Youth. Findings from their study showed that 13 percent of adolescents were abstainers. Abstainers were more likely to be female, have fewer delinquent peers, more prosocial peers, date less, have greater teacher attachment, have higher parental monitoring, be less physically mature, have lower levels of depression, and be less autonomous. However, they did not find that abstainers were socially alienated. Abstention was predicted by high levels of teacher attachment, parental monitoring, and involvement with prosocial peers. Abstention was not predicted by sadness/depression or other mental health variables. Although there are relatively few studies devoted to examining delinquency abstention, a number of studies assessing alcohol and marijuana abstention have recently been published.

There have been several studies that have compared abstainers to experimental and heavy users of alcohol. Findings from these studies are mixed. Walton and Roberts (2004) examined relations between substance use and personality traits in two studies using the five factor model of personality as well as other personality inventories. The first study tested the relationship between personality and substance abuse with a comprehensive measure of the Big Five personality traits and perfectionism and impulsivity scales. Study 1 found that heavy users of alcohol and drugs were less conscientious than moderate users or abstainers. Abstainers scored higher on conscientiousness and lower on extraversion compared to the other groups but did not score higher on neurotic over-control or emotional stability. Study 1 relied solely on selfreport data. For Study 2, observer ratings of participants' personalities were used. Findings indicated that heavy alcohol and drug users scored lower in agreeableness and conscientiousness. Abstainers scored the highest of the groups on conscientiousness and lowest on extraversion.

Leifman and colleagues (1995) compared Swedish, military eighteen to nineteen year old alcohol-abstainer males to alcohol consumers in terms of "sociability," which was defined in terms of social insecurity, number of close friends, quality of conversations with friends and school popularity. Swedish military men born 1969-1970 were broken into five groups, with 5.9 percent of the study being abstainers $(2,691$ persons) who drank $0 \mathrm{~g}$ alcohol/week, 25.3 percent being light consumers (11,563 persons) who drank $1-25 \mathrm{~g}$ alcohol/week, 53.2 percent being moderate consumers $(24,329)$ who drank $26-100 \mathrm{~g} /$ week, 13.2 percent being frequent consumers $(6,051)$ who drank $101-$ $250 \mathrm{~g} /$ week, and 2.4 percent being high consumers $(1,112)$ who drank $>250 \mathrm{~g} /$ week. For sociability, abstainers were highest in the categories "often insecure in the company of others," "unpopular in school," and "no friends or one friend." Skogen, Harvey, Henderson, Stordal, and Mykletun's (2009) study of anxiety and depression among abstainers and low-level alcohol consumers used data from the Nord-Trøndelag Health Study $(\mathrm{N}=38,930)$ in two waves. Alcohol consumption was measured by self-report while anxiety and depression were measured using the Hospital Anxiety and Depression Rating Scale. Findings indicated that abstention was related to increased odds for case-level anxiety and depression.

In a study that assessed relations between alcohol abstention and cognitive performance, Anstey and colleagues (2005) identified several key findings. Cognitively, abstainers performed worse on all measures in all age groups. More women than men were abstainers and abstainers had lower education levels. In comparison to same-age drinkers, abstainers were less likely to smoke marijuana in last twelve months and had lower levels of extroversion and behavior activation systemfun-seeking. In a study designed to directly test Shedler and Block's (1990) classic assertion that abstainers are less psychologically healthy than experimenters, Milich et al. and colleagues (2000) classified study participants into three groups: those with marijuana use by age twenty; alcohol use during 10th grade; and alcohol use at age twenty. These groups were compared at age twenty in terms of personality characteristics, deviant behavior, and psychopathology. Findings indicated that abstainers were less psychologically impaired, and were generally healthier. In a study examining psychological maladjustment among adolescents who were abstainers from marijuana use suggested that abstainers were healthier than experimenters and frequent users. Tucker, Ellickson, Collins, and Klein (2006) analyzed a longitudinal study composed of seventh graders recruited from middle schools in California and Oregon in 1985 and assessed again in 1990 (12th grade) and 1995 (age twenty three) with self-report surveys. Abstainers from marijuana fared better than experimenters and frequent users in school, family and peer relations, mental health, and behavior.

\section{Study aims}

In sum, some studies suggest that abstainers are more socially withdrawn and may suffer from anxiety and mood disorders whereas other studies suggest abstainers are quite psychologically healthy. However, extant studies of abstainers are limited in scope as exemplified by non-representative samples or lack of comprehensive mental health assessments. A clear gap in this body of work is the absence of an epidemiological study of true abstainers (i.e., substance use and externalizing behaviors) that takes into account a large swath of the life-course and is comprehensive in terms of sociodemographic and mental health assessment. The purpose of this study was to compare lifetime abstainers to non-abstainers across sociodemographic, mental health, and personality characteristics in a nationally representative sample of U.S. adults and estimate the strength of these comparisons in controlled multivariate analyses. The primary study aims are to 1) test the null hypothesis that abstainers are no more maladjusted than non-abstainers and 2) shed light on the sociodemographic characteristics of abstainers in order to advance the descriptive research database on abstainers.

\section{Method}

\section{Participants}

Study findings are based on data from the 2001-2002 National Epidemiologic Survey on Alcohol and Related Conditions (NESARC). NESARC is a nationally representative sample of 43,093 noninstitutionalized U.S. residents aged 18 years and older (Grant, Hasin, Stinson, Dawson, Chou, Ruan, \& Pickering, 2004; Grant, Stinson, Hasin, Dawson, Chou, Ruan, \& Pickering, 2004.; Grant, Dawson, Stinson, Chou, Kay, \& Pickering, 2003). The survey gathered sociodemographic data and extensive information about substance use and co-morbid psychiatric disorders, including personality disorders, from individuals living in households and group settings such as shelters, college dormitories, and group homes in all fifty states and the District of Columbia. NESARC utilized a multistage cluster sampling design, oversampling young adults, Hispanics, and African-Americans in the interest of obtaining reliable statistical estimation in these subpopulations, and to ensure appropriate representation of racial/ethnic subgroups. The overall response rate was 81 percent. Data were weighted at the individual and household levels to adjust for oversampling and non-response on demographic variables (i.e., age, race/ethnicity, sex, region, and place of residence). Data were also adjusted to be representative (based on region, age, race, and ethnicity) of the U.S. adult population as assessed during the 2000 Census. Study participants provided fully informed consent. The U.S. Census Bureau and the U.S. Office of Management and Budget approved the research protocol and informed consent procedures.

\section{Assessment}

Data were collected through face-to-face structured psychiatric interviews conducted by U.S. Census workers trained by the National Institute on Alcohol Abuse and Alcoholism and U.S. Census Bureau. Interviewers administered the Alcohol Use Disorder and Associated 
Disabilities Interview Schedule - DSM-IV version (AUDADIS-IV), which provides diagnoses for mood, anxiety, personality, and substance use disorders. The AUDADIS-IV has shown good-to-excellent reliability in assessing alcohol and drug use in the general population (Blanco, Grant, Petry, Simpson, Alegria, Liu, \& Hasin, 2008; Grant, Harford, Dawson, Chou, \& Pickering, R., 1995; Hasin, Carpenter, McCloud, Smith, \& Grant, 1997). Specific disorders included major depression, dysthymia, and bipolar disorder, social phobia, generalized anxiety disorder, panic disorder, specific phobia, and pathological gambling. Lifetime alcohol (alcohol abuse/dependence) and drug (abuse/dependence on nicotine, heroin, hallucinogens, cocaine/crack, marijuana, stimulants, painkillers, tranquilizers, and sedatives) were also included. In addition to antisocial personality disorder, other personality disorders assessed included avoidant, dependent, obsessive-compulsive, paranoid, schizoid, and histrionic disorders. A host of socio-demographic and background characteristics were also collected in these interviews. These included age, gender, race and ethnicity, income, education, marital status, nativity, region of the country, urbanicity, and employment status. Family history of antisocial behavior based on any parental or sibling history of antisocial behavior was also assessed. Response categories for region of residence in U.S., urbanicity, race/ethnicity, sex, age, marital status, educational background, unemployment status, and individual and family income are listed in Table 1.

\section{Defining abstainers}

Lifetime abstaining from alcohol, drug use, and antisocial behaviors was assessed using a total of forty one items. Eight of these items assessed specific types of lifetime substance use (alcohol, nicotine, hallucinogens, cocaine/crack, marijuana, stimulants, tranquilizers, and sedatives) and questions were worded as follows for alcohol use: In your entire life, have you had at least one drink of any kind of alcohol, not counting small tastes or sips? And drug use as follows: Have you EVER used any of these medicines or drugs? The remaining thirty-three items were part of the conduct disorder and antisocial behavior interview module that all NESARC participants were asked. Sample items include, "In your ENTIRE LIFE, did you EVER have a time when you bullied or pushed people around or tried to make them afraid of you?" and "In your ENTIRE LIFE, did you EVER Steal anything from someone or someplace when no one was around? NESARC respondents who answered no to all forty one of these items were defined as abstainers. The reliability of these items test-retest analyses indicated adequate stability $(r=0.69)$ [Grant et al., 2003]. The internal consistency reliability for the entire antisocial behavior criterion set was good ( $\alpha=0.86)$ [Grant et al., 1995] as has the convergent relations of items (Vaughn, Fu, DeLisi, Beaver, Terrell, Perron, \& Howard, 2009; Vaughn, Fu, DeLisi, Wright, Beaver, Perron, \& Howard, 2010a, b).

Table 1

Sociodemographic characteristics of abstainer and non-abstainers by gender

\begin{tabular}{|c|c|c|c|c|c|c|}
\hline Characteristic & $\begin{array}{l}\text { Male abstainers } \\
(\mathrm{N}=1,038) \\
\% \mathrm{CI}\end{array}$ & $\begin{array}{l}\text { Female abstainers } \\
(\mathrm{N}=3,742) \\
\% \mathrm{CI}\end{array}$ & $\begin{array}{l}\text { Male } \\
\text { non-abstainers } \\
(\mathrm{N}=17,480) \\
\% \mathrm{CI}\end{array}$ & $\begin{array}{l}\text { Female } \\
\text { non-abstainers } \\
(\mathrm{N}=20,833) \\
\% \mathrm{CI}\end{array}$ & $\begin{array}{l}\text { Male abstainers } \\
\text { versus male } \\
\text { non-abstainers } \\
\text { AOR } \\
\% \mathrm{CI}\end{array}$ & $\begin{array}{l}\text { Female abstainers } \\
\text { versus female } \\
\text { non-abstainers } \\
\text { AOR } \\
\% \mathrm{CI}\end{array}$ \\
\hline \multicolumn{7}{|l|}{ Race } \\
\hline Hispanic & $20.05(15.76-25.15)$ & $18.63(14.17-24.10)$ & $11.84(9.54-14.61)$ & $9.64(7.82-11.82)$ & $1.18(0.86-1.62)$ & $1.39(1.15-1.67)$ \\
\hline Asian/Alaska/Indian/Native American & $14.41(10.59-19.30)$ & $14.32(11.51-17.68)$ & $6.06(5.10-7.20)$ & $5.18(4.47-6.00)$ & $1.90(1.37-2.62)$ & $2.57(2.08-3.17)$ \\
\hline African American & $14.12(11.22-17.62)$ & $14.68(12.82-16.76)$ & $9.88(8.74-11.16)$ & $11.51(10.16-13.00)$ & $1.71(1.34-2.18)$ & $1.74(1.50-2.02)$ \\
\hline White & $51.43(44.77-58.04)$ & $52.37(46.97-57.71)$ & $72.22(68.99-75.22)$ & $73.68(70.90-76.28)$ & 1.00 & 1.00 \\
\hline \multicolumn{7}{|l|}{ Nativity } \\
\hline Born in the U.S. & $65.06(57.30-72.09)$ & $66.33(59.72-72.36)$ & $86.01(82.87-88.66)$ & $89.05(86.72-91.02)$ & $0.36(0.28-0.45)$ & $0.28(0.24-0.32)$ \\
\hline Born in a foreign country & $34.94(27.91-42.70)$ & $33.67(27.64-40.28)$ & $13.99(11.34-17.13)$ & $10.95(8.98-13.28)$ & 1.00 & 1.00 \\
\hline \multicolumn{7}{|l|}{ Age (years) } \\
\hline $18-34$ & $38.59(35.06-42.25)$ & $27.51(25.15-30.01)$ & $32.34(31.22-33.48)$ & $30.93(29.96-31.91)$ & $0.67(0.52-0.86)$ & $0.38(0.32-0.45)$ \\
\hline $35-49$ & $25.82(22.34-29.64)$ & $22.53(20.52-24.67)$ & $32.17(31.25-33.10)$ & $31.84(31.01-32.67)$ & $0.58(0.45-0.75)$ & $0.34(0.29-0.40)$ \\
\hline $50-64$ & $19.35(16.43-22.63)$ & $19.70(18.01-21.51)$ & $21.34(20.65-22.06)$ & $21.16(20.45-21.89)$ & $0.76(0.58-0.99)$ & $0.46(0.39-0.54)$ \\
\hline $65+$ & $16.24(13.47-19.46)$ & $30.26(27.32-33.37)$ & $14.15(13.39-14.93)$ & $16.08(15.40-16.78)$ & 1.00 & 1.00 \\
\hline \multicolumn{7}{|l|}{ Education } \\
\hline Less than high school & 19.89 (17.35-22.69) & 27.38 (24.96-29.95) & $15.73(14.69-16.83)$ & $13.41(12.56-14.31)$ & $1.04(0.81-1.34)$ & $1.63(1.44-1.86)$ \\
\hline High school graduate & $29.13(25.48-33.06)$ & $31.54(29.16-34.02)$ & $28.72(27.37-30.12)$ & $29.59(28.57-30.63)$ & $1.13(0.93-1.37)$ & $1.32(1.18-1.48)$ \\
\hline Some college or more & $50.98(47.01-54.94)$ & $41.08(38.85-43.34)$ & $55.54(53.98-57.10)$ & $57.01(55.82-58.19)$ & 1.00 & 1.00 \\
\hline \multicolumn{7}{|l|}{ Income } \\
\hline $0-19,999$ & $26.39(22.87-30.24)$ & 37.63 (35.64-39.67) & $19.40(18.30-20.56)$ & $25.48(24.44-26.54)$ & $1.21(0.88-1.67)$ & $1.76(1.47-2.11)$ \\
\hline $20,000-34,999$ & $19.53(16.87-22.49)$ & $21.86(20.30-23.52)$ & $20.16(19.26-21.09)$ & $19.84(19.07-20.62)$ & $0.97(0.74-1.28)$ & $1.46(1.22-1.75)$ \\
\hline $35,000-69,999$ & $32.71(28.60-37.11)$ & $27.71(25.37-30.18)$ & $33.60(32.50-34.73)$ & $31.30(30.49-32.13)$ & $1.11(0.83-1.48)$ & $1.45(1.19-1.78)$ \\
\hline $70,000+$ & $21.37(17.96-25.23)$ & $12.79(10.93-14.92)$ & $26.83(25.10-28.63)$ & $23.38(22.04-24.78)$ & 1.00 & 1.00 \\
\hline \multicolumn{7}{|l|}{ Marital status } \\
\hline Never married & $31.54(28.17-35.11)$ & $15.95(15.31-18.73)$ & $23.36(22.19-24.57)$ & $18.49(17.52-19.51)$ & $1.59(1.25-2.02)$ & $1.04(0.90-1.20)$ \\
\hline Widowed/separated/divorced & $7.51(6.23-9.03)$ & $24.24(22.55-26.02)$ & $12.04(11.47-12.63)$ & $22.41(21.72-23.10)$ & $0.68(0.54-0.85)$ & $0.70(0.62-0.78)$ \\
\hline Married/cohabitating & $60.95(57.35-64.44)$ & $58.81(56.70-60.88)$ & $64.60(63.44-65.75)$ & $59.10(57.96-60.24)$ & 1.00 & 1.00 \\
\hline \multicolumn{7}{|l|}{ Urbanicity } \\
\hline Central city & $35.40(28.34-43.15)$ & $31.71(24.87-39.43)$ & $28.96(24.97-33.31)$ & $29.43(25.50-33.69)$ & $1.04(0.88-1.23)$ & $0.86(0.74-1.02)$ \\
\hline Rural/suburban & $64.60(56.85-71.66)$ & $68.29(60.57-75.13)$ & $71.04(66.69-75.03)$ & $70.57(66.31-74.50)$ & 1.00 & 1.00 \\
\hline \multicolumn{7}{|l|}{ Region } \\
\hline Northeast & $17.62(9.97-29.23)$ & $16.41(9.18-27.60)$ & $19.64(13.83-27.13)$ & $20.35(14.41-27.95)$ & $0.83(0.61-1.14)$ & $0.82(0.58-1.15)$ \\
\hline Midwest & $13.48(9.21-19.31)$ & $16.04(10.99-22.82)$ & $23.84(18.06-30.77)$ & $24.15(18.16-31.36)$ & $0.65(0.46-0.93)$ & $0.89(0.70-1.14)$ \\
\hline South & $42.93(33.48-52.93)$ & $44.73(35.75-54.06)$ & $34.51(28.46-41.11)$ & $33.92(27.89-40.52)$ & $1.24(0.95-1.62)$ & $1.56(1.22-1.98)$ \\
\hline West & $25.97(17.07-37.42)$ & $22.83(14.15-34.67)$ & $22.01(15.86-29.71)$ & $21.58(15.69-28.91)$ & 1.00 & 1.00 \\
\hline \multicolumn{7}{|l|}{ Employment status } \\
\hline Unemployed & $6.09(4.42-8.35)$ & $4.42(3.49-5.60)$ & $9.94(9.33-10.59)$ & $8.45(7.90-9.04)$ & $0.47(0.34-0.67)$ & $0.46(0.35-0.59)$ \\
\hline Employed & $93.91(91.65-95.58)$ & $95.58(94.40-96.51)$ & $90.06(89.41-90.67)$ & $91.55(90.96-92.10)$ & 1.00 & 1.00 \\
\hline
\end{tabular}

CI: confidence interval, AOR: adjusted odds ratio. OR values that are in bold are statistically significant. 


\section{Statistical analyses}

Respondents who responded "no" to all forty one items indexing lifetime substance use (alcohol, marijuana, nicotine, heroin, cocaine, hallucinogens etc.) and antisocial behaviors (cutting class, hurting others, reckless driving, fighting etc.) were designated as abstainers. Abstainers were then compared to non-abstainers stratified by gender male abstainers compared to male non-abstainers and female abstainers compared to female abstainers. Weighted prevalence estimates and standard errors were computed using SUDAAN Version 9.0. (RTI, 2004). This system implements a Taylor series linearization to adjust standard errors of estimates for complex survey sampling design effects including clustered data. Multivariate logistic regression analyses were conducted to assess the association of sociodemographic and lifetime psychiatric comorbidity with abstainer and non-abstaining status while controlling for sociodemographic covariates and lifetime psychiatric disorders. In this way, we were able to isolate the effect of each diagnostic category on abstaining and non-abstainer. Adjusted odds ratios (AORs) and 95 percent confidence intervals are presented to reflect association strength. Adjusted odds ratios were considered statistically significant only if associated confidence intervals did not include the value 1.0.

\section{Results}

Sociodemographic characteristics of abstainers and non-abstainers by gender

Table 1 shows sociodemographic characteristics of adults with and without a lifetime history abstaining stratified by gender with odds ratios adjusted for other socidemographic variables. Abstainers $(N=4,780$, 11 percent) were composed largely of females (74.3 percent). There were no significant differences in gender composition among nonabstainers $(\mathrm{N}=38,313)$. With respect to race/ethnicity, Hispanic abstainers were more likely to be female $(\mathrm{OR}=1.39$, 95 percent $\mathrm{CI}=1.15-1.67)$, Asians, both male $(\mathrm{OR}=1.90$, 95 percent $\mathrm{CI}=1.37$ 2.62) and female ( $\mathrm{OR}=2.57,95$ percent $\mathrm{CI}=2.08-3.17)$, were more likely to be abstainers compared to Whites as were African-American males $(\mathrm{OR}=1.71,95$ percent $\mathrm{CI}=1.34-2.18)$ and females (1.74, 95 percent $\mathrm{CI}=1.50-2.02$ ). Persons born in the U.S. were significantly less likely to be abstainers compared to persons born in a foreign country. Younger age categories were significantly less likely to be abstainers than older age categories. Lower levels of education and income were significantly lower among female abstainers only. However, abstainers, both male and female, were less likely to be unemployed.

Both male and female abstainers were significantly less likely to be widowed, separated, or divorced compared to non-abstainers. Regionally, female abstainers were significantly more likely to be from the South ( $\mathrm{OR}=1.56$, 95 percent $\mathrm{CI}=1.22-1.98)$ than the West and male abstainers were less likely to reside in the Midwest than the West.

\section{Multivariate logistic regression analyses examining associations between abstainers and non-abstainers by gender}

Table 2 compares prevalence rates of lifetime psychiatric disorders of abstainers versus non-abstainers stratified by gender. Recall odd ratios are adjusted for sociodemographic factors (i.e., race, education, marital status, age, income, region, and urbanicity) and previously described lifetime DSM-IV psychiatric disorders. With respect to lifetime mood disorders, both male and female abstainers were significantly less likely to be diagnosed with major depressive disorder, and females only were less likely to be diagnosed with bipolar disorder. Female and male abstainers were also significantly less likely to be diagnosed with any specific phobias. Abstainers were also significantly less likely to have a family history of antisocial behavior. Finally, personality disorder analyses indicated that male abstainers were significantly less likely to be diagnosed with obsessive-compulsive, paranoid, and schizoid personality disorders compared to male abstainers. Female abstainers were significantly less likely to be diagnosed with paranoid and histrionic personality disorders compared to female non-abstainers. There was no psychiatric disorder where abstainers were more likely to meet diagnostic criteria for compared to non-abstainers.

Table 2

Psychiatric correlates of male and female adults with and without a lifetime history of abstaining behavior

\begin{tabular}{|c|c|c|c|c|c|c|}
\hline Psychiatric disorder & $\begin{array}{l}\text { Male abstainers } \\
(\mathrm{N}=1,038) \\
\%\left(95 \% \mathrm{Cl}^{\mathrm{a}}\right)\end{array}$ & $\begin{array}{l}\text { Female abstainers } \\
(\mathrm{N}=3,742) \\
\%\left(95 \% \mathrm{Cl}^{\mathrm{a}}\right)\end{array}$ & $\begin{array}{l}\text { Male non-abstainers } \\
(\mathrm{N}=17,480) \\
\%(95 \% \mathrm{CI})\end{array}$ & $\begin{array}{l}\text { Female non-abstainers } \\
(\mathrm{N}=20,833) \\
\%(95 \% \mathrm{CI})\end{array}$ & $\begin{array}{l}\text { Male abstainers } \\
\text { AOR }(95 \% \mathrm{CI})\end{array}$ & $\begin{array}{l}\text { Female abstainers } \\
\text { AOR }(95 \% \mathrm{CI})\end{array}$ \\
\hline \multicolumn{7}{|l|}{ Mood disorders } \\
\hline Major depressive disorder & $2.86(1.83-4.43)$ & $7.30(6.00-8.85)$ & $12.31(11.68-12.97)$ & $23.11(22.09-24.16)$ & $0.40(0.27-0.60)$ & $0.47(0.39-0.57)$ \\
\hline Bipolar disorder & $1.41(0.74-2.70)$ & $1.43(0.99-2.07)$ & $5.87(5.45-6.34)$ & $6.32(5.83-6.83)$ & $0.54(0.28-1.06)$ & $0.56(0.38-0.83)$ \\
\hline Dysthymia & $0.90(0.38-2.15)$ & $1.75(1.29-2.36)$ & $3.13(2.81-3.48)$ & $6.09(5.66-6.56)$ & $1.10(0.50-2.41)$ & $0.76(0.54-1.06)$ \\
\hline \multicolumn{7}{|l|}{ Anxiety disorders } \\
\hline Panic disorder & $0.55(0.22-1.34)$ & $2.19(1.60-2.99)$ & $2.72(2.43-3.05)$ & $5.78(5.34-6.26)$ & $0.46(0.18-1.17)$ & $0.77(0.55-1.08)$ \\
\hline Social phobia & $1.21(0.54-2.70)$ & $2.67(1.98-3.59)$ & $4.37(3.94-4.84)$ & $6.17(5.66-6.72)$ & $0.78(0.34-1.81)$ & $1.09(0.79-1.49)$ \\
\hline Specific phobia & $1.52(0.84-2.72)$ & $5.61(4.59-6.84)$ & $6.42(5.89-7.01)$ & $13.45(12.64-14.31)$ & $0.41(0.23-0.72)$ & $0.60(0.49-0.75)$ \\
\hline Generalized anxiety disorder & $0.73(0.26-2.04)$ & $1.67(1.20-2.33)$ & $2.94(2.58-3.33)$ & $5.95(5.46-6.48)$ & $0.93(0.33-2.62)$ & $0.80(0.57-1.13)$ \\
\hline \multicolumn{7}{|l|}{ Psychotic disorder } \\
\hline Substance use disorders & $0.24(0.04-1.26)$ & $0.22(0.09-0.53)$ & $0.85(0.68-1.06)$ & $0.89(0.75-1.05)$ & $0.53(0.09-3.07)$ & $0.53(0.22-1.32)$ \\
\hline Alcohol use disorder & 0.00 & 0.00 & $44.32(42.37-46.29)$ & $22.71(21.44-24.03)$ & * & * \\
\hline Illicit drug use disorder & 0.00 & 0.00 & $7.32(6.74-7.95)$ & $4.35(3.94-4.80)$ & * & * \\
\hline Marijuana Use disorder & 0.00 & 0.00 & $12.44(11.65-13.27)$ & $6.28(5.76-6.84)$ & * & $*$ \\
\hline Pathological Gambling & 0.00 & 0.00 & $0.67(0.54-0.84)$ & $0.26(0.20-0.35)$ & $*$ & $*$ \\
\hline $\begin{array}{l}\text { Family history of antisocial } \\
\text { Behavior }\end{array}$ & $7.52(5.76-9.76)$ & $10.18(8.80-11.76)$ & $22.03(20.87-23.24)$ & $26.43(25.26-27.64)$ & $0.44(0.33-0.58)$ & $0.50(0.43-0.58)$ \\
\hline \multicolumn{7}{|l|}{ Personality disorders } \\
\hline Antisocial PD & $*$ & $1.89(1.69-2.12)$ & $5.84(5.33-6.38)$ & $2.20(1.96-2.47)$ & $*$ & $*$ \\
\hline Avoidant PD & $0.39(0.08-1.82)$ & $1.08(0.76-1.53)$ & $2.00(1.73-2.30)$ & $3.04(2.70-3.41)$ & $0.74(0.14-3.80)$ & $1.35(0.86-2.14)$ \\
\hline Obsessive-Compulsive PD & $2.07(1.27-3.35)$ & $3.22(2.47-4.20)$ & $8.19(7.63-8.79)$ & $8.65(8.08-9.26)$ & $0.53(0.31-0.89)$ & $0.79(0.57-1.09)$ \\
\hline Paranoid PD & $0.35(0.17-0.75)$ & $1.46(1.04-2.04)$ & $4.02(3.62-4.46)$ & $5.53(5.09-6.00)$ & $0.27(0.12-0.59)$ & $0.54(0.36-0.81)$ \\
\hline Schizoid PD & $0.27(0.10-0.77)$ & $0.97(0.64-1.46)$ & $3.35(3.00-3.73)$ & $3.42(3.11-3.76)$ & $0.19(0.07-0.56)$ & $0.75(0.48-1.17)$ \\
\hline Histrionic PD & $0.33(0.09-1.14)$ & $0.28(0.14-0.56)$ & $1.97(1.72-2.27)$ & $2.05(1.82-2.30)$ & $0.58(0.16-2.10)$ & $0.42(0.20 \mathrm{~g}-0.87)$ \\
\hline
\end{tabular}

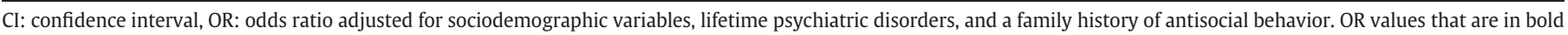
are statistically significant. 


\section{Discussion}

To our knowledge, this is the largest national study comparing abstainers with non-abstainers. The reported prevalence of abstaining was 11 percent. The overall prevalence for females (17.9 percent) was much higher than males (5.9 percent). Several important empirical trends emerged from our study. Demographically, both male and female abstainers were significantly more likely to be Asian and African-American and less likely to have been born in the U.S. Abstainers although less likely to have finished high school and earning less income than non-abstainers were significantly less likely to be unemployed.

These findings suggest that cultural features may play a substantial role in the formation of abstaining behavior. We speculate that one of these cultural forces may be religion. Our findings showed that female abstainers were 51 percent more likely to be from the southern U.S. where religiosity and associated restrictive practices are more concentrated. A study by Epler, Sher, and Piasecki (2009) looked at the reason for abstaining or limiting drinking in a large sample of college students. Reasons for abstaining or limiting drinking (RALD) based on upbringing or religion was associated with abstaining from alcohol. Also, those who started to abstain after college reported an increase in the importance of RALD associated with loss of control and religiosity compared to those who did not abstain after college. That abstainers were more likely to be born outside of the U.S. suggests that cultural practices brought from other countries may serve to buffer or protect these persons from social practices in the U.S. where social drinking and episodic engagement in misbehavior during adolescence is normative. Another explanation could be greater stigma among persons from particular countries outside the U.S. to admit their drinking, drug use, or externalizing behavior. Whatever the reasons, study findings suggest that the adolescent-limited pathway of normalized delinquent behavior postulated by Moffitt (1993) may not be universal.

The next set of empirical findings revealed important insights into the abstaining phenomenon. Following adjustments for numerous confounding variables, abstainers were significantly less likely to evidence a history of a major depressive disorder, bipolar disorder (females only), social phobia, have a family history of antisocial behavior, paranoid personality disorder, obsessive-compulsive personality disorder (males only), schizoid personality disorder (males only), and histrionic personality disorder (females only). There was no mental health disorder where abstainers were significantly more likely to possess a mental health disorder in comparison with non-abstainers. These findings do not support the results of some prior studies (Shedler \& Block, 1990; Skogen, Harvey, Henderson, Stordal, \& Mykletun, 2009) or notions about abstainers being more socially anxious or possessing a related mental health disorder. Intriguingly, the findings of regarding family history of antisocial behavior suggest that not only social learning and modeling may be involved in abstaining behavior but also genetics. Abstainer may possess, for example, protective alleles that mitigate risk and seeking out of risky environments and deviant peers (Boutwell \& Beaver, 2008). Just as the NESARC has provided helpful in assessing antisocial behaviors (Vaughn et al., 2009; Vaughn et al., 2010a, b), so too is its relevance for abstaining, prosocial behaviors.

Study findings stand in stark contrast with recent research demonstrating the existence of a severely antisocial 5 percent subgroup. Using latent class methodology involving the same national representative sample Vaughn et al., 2010 revealed that 5 percent of the sample had engaged in a wide swath of antisocial behavior over the life-course is strongly associated with extensive mental health problems including bipolar disorder and multiple phobias. Future studies of abstainer's and the severe 5 percent can fruitfully build on these research studies.

\section{Limitations}

Study findings should be interpreted in light of several limitations. First, given that the study data are cross-sectional, temporal ordering of variables does not permit firm conclusions to be drawn with regard to causation. Therefore, findings cannot clarify the etiologic relationship between abstaining and its correlates. The propensity to abstain may also involve particular phenotypic characteristics that also include the propensity toward prosocial behavior in general. However, findings do suggest that abstaining and psychological health is intertwined. Prospective longitudinal study designs beginning earlier in the life course that examine the role of cultural forces on individual dispositional elements dynamically over time are necessary to elucidate the causal structure of abstaining behavior. An additional limitation is that the NESARC excludes persons under age eighteen and therefore relies on retrospective respondent recall of abstaining over potentially long swaths of time. This potentially can lead to underreporting or to bias in reporting with younger respondents recalling better than older respondents. Although the NESARC is a nationally representative sample, it is uncertain what the comparative effects between abstainer and non-abstainers would be if enriched correctional or clinical samples were employed. Further, data on abstainers did not included important situational and precipitating factors in the decision-making process of abstainers. Future studies on abstainers would benefit from incorporating these types of natural history features into data collection. Despite these limitations, findings from this study provide new and important epidemiologic insights into phenomenon of abstaining behavior in the United States.

\section{References}

Anstey, K. J., Windsor, T. D., Rodgers, B., Jorm, A. F., \& Christensen, H. (2005). Lower cognitive test scores observed in alcohol abstainers are associated with demographic, personality and biological factors: The PATH Through Life Project. Addiction, 100, 1291-1301.

Blanco, C., Grant, J., Petry, N. M., Simpson, H. B., Alegria, A., Liu, S., et al. (2008). Prevalence and correlates of shoplifting in the United States: Results from the National Epidemiologic Survey on Alcohol and Related Conditions (NESARC). American Journal of Psychiatry, 165(7), 905-913.

Boutwell, B. B., \& Beaver, K. M. (2008). A biosocial explanation of delinquency abstention. Criminal Behaviour and Mental Health, 18, 59-74.

DeLisi, M. (2001). Scaling archetypal criminals. American Journal of Criminal Justice, 26 $77-92$.

Elliott, D. S., Huizinga, D., \& Menard, S. (1989). Multiple problem youth: Delinquency, substance use, and mental health problems. New York: Springer-Verlag.

Epler, A. J., Sher, K. J., \& Piasecki, T. M. (2009). Reasons for abstaining or limiting drinking: A developmental perspective. Psychology of Addictive Behaviors, 23, 428-442.

Grant, B. F., Dawson, D. A., Stinson, F. S., Chou, P. S., Kay, W., \& Pickering, R. (2003). The Alcohol Use Disorder and Associated Disabilities Interview Schedule-IV (AUDADIS-IV): Reliability of alcohol consumption, tobacco use, family history of depression and psychiatric diagnostic modules in a general population sample. Drug and Alcohol Dependence, 71, 7-16.

Grant, B. F., Harford, T., Dawson, D. A., Chou, P. S., \& Pickering, R. (1995). The Alcohol Use Disorder and Associated Disabilities Interview schedule (AUDADIS): Reliability of alcohol and drug modules in a general population sample. Drug and Alcohol Dependence, 39, 37-44.

Grant, B. F., Hasin, D. S., Stinson, F. S., Dawson, D. A., Chou, S. P., Ruan, W. J., et al (2004a). Prevalence, correlates, and disability of personality disorders in the United States: Results from the National Epidemiologic Survey of Alcohol and Related Conditions. The Journal of Clinical Psychiatry, 65(7), 948-958.

Grant, B. F., Stinson, F. S., Hasin, D. S., Dawson, D. A., Chou, S. P., Ruan, W. J., et al. (2004b). Co-occurrence of 12-month alcohol and drug use disorders and personality disorders in the United States: Results from the National Epidemiologic Survey on Alcohol and Related Conditions. Archives of General Psychiatry, 61, $361-368$.

Hasin, D., Carpenter, K. M., McCloud, S., Smith, M., \& Grant, B. F. (1997). The alcohol use disorders and associated disabilities interview schedule (AUDADIS): Reliability of alcohol and drug modules in a clinical sample. Drug and Alcohol Dependence, 44, 133-141.

Leifman, H., Kuhlhorn, E., Allebeck, P., Andreasson, S., \& Romelsjo, A. (1995). Abstinence in late adolescence - Antecedents to and covariates of a sober lifestyle and its consequences. Social Science \& Medicine, 41, 113-121.

Milich, R., Lynam, D. R., Zimmerman, R., Logan, T. K., Martin, C., \& Leukefeld, C., et al. (2000). Differences in adult psychopathology among drug abstainers, experimenters, and frequent users. Journal of Substance Abuse, 11, 69-88. 
Moffitt, T. E. (1993). Adolescence-limited and life-course-persistent antisocial behavior: A developmental taxonomy. Psychological Review, 100, 674-701.

Piquero, A. R., Brezina, T., \& Turner, M. G. (2005). Testing Moffitt's account of delinquency abstention. Journal of Research in Crime and Delinquency, 42, 27-54.

Research Triangle Institute: Software for survey data analysis, SUDAAN. Version 9.0. (2004). Research Triangle Park, NC: Research Triangle Institute.

Shedler, J., \& Block, J. (1990). Adolescent drug use and psychological health: A longitudinal inquiry. American Psychologist, 45, 612-630.

Skogen, J. C., Harvey, S. B., Henderson, M., Stordal, E., \& Mykletun, A. (2009). Anxiety and depression among abstainers and low-level alcohol consumers: The NordTrøndelag Health Study. Addiction, 104, 1519-1529.

Tucker, J. S., Ellickson, P. L., Collins, R. L., \& Klein, D. J. (2006). Does solitary substance use increase adolescents' risk for poor psychosocial and behavioral outcomes? A 9-year longitudinal study comparing solitary and social users. RAND Corporation, Santa Monica, CA, U.S.
Vaughn, M. G., Fu, Q., DeLisi, M., Beaver, K. M., Perron, B. E., Howard, M. O. (2010). Criminal victimization and comorbid substance use and psychiatric disorders in the United States: Results from the NESARC. Annals of Epidemiology, 20, 281-288.

Vaughn, M. G., Fu, Q., DeLisi, M., Beaver, K. M., Terrell, K., Perron, B. E., et al. (2009). Correlates of cruelty to animals in the United States: Results from the national epidemiologic survey on alcohol and related conditions. Journal of Psychiatric Research, 43, 1213-1218.

Vaughn, M. G. Fu, Q DeLisi, M. Wright, J. P. Beaver K. M. Perron, B. E \& Howard, M. 0. (2010). Prevalence and correlates of fire-setting in the United States: Results from the national epidemiologic survey on alcohol and related conditions. Comprehensive Psychiatry, 51, 217-223.

Walton, K. E., \& Roberts, B. W. (2004). On the relationship between substance use and personality traits: Abstainers are not maladjusted. Journal of Research in Personality, $38,515-535$. 